\title{
Family's Role in Achieving Language Affiliation among Children: A Comparative Study Applied to Some Families
}

\author{
Aljohara Fahad Al Saud \\ Department of Early Education, Faculty of Education \\ King Saud University \\ Email: aalsaud@ksu.edu.sa
}

Received: 5/27/2021

Accepted: 8/22/2021

Published: 9/24/2021

\section{Abstract}

Identifying language affiliation among children for family immigrants is crucial for one's language identity. This study aimed to determine the role played by Arab families in the Kingdom of Saudi Arabia, Austria, and Britain to attain language affiliation among their children. It also aims to identify the challenges facing families living in these countries in achieving language affiliation among their children. The study population consisted of all the families that live in the Kingdom of Saudi Arabia, in addition to all the Arab families that live in Austria and Britain and the study sample included (120) parents. The researcher adopted the descriptive-analytical approach and used the questionnaire as the study tool. The study reached several results; first, the role played by families in the Kingdom of Saudi Arabia, Austria, and United Kingdom to attain language affiliation among their children got a high degree of response. Second, the challenges facing activating the family's role in attaining language affiliation of their children in the Kingdom of Saudi Arabia and Austria have got a high degree of response, while in Britain, they obtained a very high degree of response. The study recommended involving all family members in accessing different and creative ways of practicing their native language and activating the role of social media in developing the language affiliation of children.

Keywords: challenges, children, family role, language affiliation, language identity

Cite as: Al Saud, A. F. (2021). Family's Role in Achieving Language Affiliation among Children: A Comparative Study Applied to Some Families. Arab World English Journal, 12 (3) 111-128.

DOI: https://dx.doi.org/10.24093/awej/vol12no3.8 


\section{Introduction}

The family is the first nucleus of socialization, the first future of the child, and responsible for their normal social upbringing. The family devotes to providing a child with standards, behaviors and language that help facilitate communication. It can therefore be said that the family contributes to a prominent and pivotal role in the mental, social and linguistic development of children, especially at an early age. Children are born with instincts to obtain social experience, knowledge, and behavior. This could be indicated when receiving first lessons in social/humanitarian relations from their family in general and from their parents. This would contribute to their balanced personality, forming of their consciousness and awareness of themselves and their social surroundings, thereby ensuring positive communication with others and adapting to them according to positive mutual relations (Halawa, 2011).

Therefore, it can be said that the family is one of the most important institutions of socialization and the most potent group influencing the behavior of the individual in which s/he receives the $\mathrm{ABCs}$ behavior. It is the most appropriate social institution to initiate the socialization process; it takes the primary responsibility for bringing up children during the first years of their lives. It is also a distinct nature in social construction and determines the position of children in their subculture which affects social upbringing in the later stages of their lives and prepares and sends them to institutions and social systems (Muhammad, 2012).

Language is a successful means of communication between individuals and groups, through which ideas and feelings are communicated from one individual to another and from one group to another. The language has clear and specific meanings in the society in which it is delivered (Hamida, 2010).

Many factors are affecting linguistic development and vocabulary of children, and family factor comes at the forefront of those factors (Das \& Priya, 2017). The family undoubtedly plays a prominent role in establishing the linguistic bases of children from an early age. Children benefit significantly from the linguistic richness and linguistic knowledge that parents give them at home (Tamis-lemonda \& Rodriguez, 2009).

Hence, it can be said that what children need to develop their language skills is to provide opportunities to communicate with others and adults' assistance to practice and try out the language (Hamida, 2010). This prompted many researchers to assert that the family played a pivotal role in developing children's vocabulary. Family is the first communication channel on which children depend for expressing their thoughts through using the language (Cole, 2008).

Linguistic development is considered one of the social areas reflected in the psychological orientation of the creation of interpersonal social relationships, whether by using writing or speaking patterns. This is what Jin (2015) points out that linguistic development arises within human social relations. It is handled by semantic symbols such as the use of written or spoken language. In this way, it can be said that linguistic development is based on the interpersonal psychological pattern that is reflected through social relationships based on their use of a particular language with each other. 
Language is defined as the systematic, structured means by which symbols and meanings are arranged in a specific way to serve the objectives of the communication process (Das \& Priya, 2017). Altaie (2009) defines language as "a set of phoneme traditions inherited by the linguistic community from its ancestors, so it adheres to it, meaning that the individual who speaks the language of the society in which he grew up uses its sounds, formulas, vocabulary and composition according to certain usage rules of the language"(p.199). For the current study aims, language is the primary means of communication and transmission of ideas between the family and children through the use of signifiers and symbols with clear and specific meanings, regardless of the environment, be Arab or foreign.

Language affiliation is a term usually used to indicate a personal sense of belonging to a language (Chung, 2014). Language affiliation can also be defined as that identity or attachment which an individual feels toward a language regardless of whether s/he really belongs to the social group in which it is spoken (Caine, 2008). The researcher considers it as a form of connection between children and their native language that helps to maintain their own language identity, which distinguishes them from others.

The term role is defined as "a socially expected behavior pattern usually determined by an individual's status in a particular society" (Merriam-Webster Dictionary, 2020, para. 2). For the current study aim, the role is defined by the author as "the characteristics associated with the behavior of one or a group of individuals in a particular societal context". The role theory can also be relied upon as one of the means that allows the individual to represent the relationship between their language affiliation and their role as a member of their family as a more comprehensive position or role in a specific social situation outside the family. This is what Mead pointed out (2013) when he emphasized that role theory is used with interactive approaches to facilitate the formation of a close link between an individual's independent identity and their societal role according to subjective characteristics that entail individual's perceptual self-representation. Those characteristics include language affiliation and roles that exist within the environment of various families. These personal characteristics are also a social product whose significance stems from social interactions, provided that these characteristics reflect the societal roles that follow a hierarchical pattern differently from one individual to another according to the context and the social situation in which they exist.

Dean-El (2019) also emphasizes that role theory can be addressed through five directions, including functional role theory, role theory from the perspective of symbolic interaction, structural role theory, organizational role theory, as well as cognitive role theory. These five approaches help researchers focus on the different interactions between individuals at the organizational and social levels (Dean-El, 2019).

According to Bou Raad, Hallit, Iskandar, Zeenny, and Salameh (2017), the dimensions of the role theory are represented in the role, aspirations, and reaction of behavior. They emphasized that the role theory includes three basic dimensions: (1) the role which includes behaviors of characteristics that are associated with a specific social position, (2) aspirations that include different customs, beliefs, and preferences, and (3) reaction of behavior which includes the positive and negative reaction that arises as a result of the emergence of specific behavior. 
The family is the first institution of socialization to which the individual belongs. Therefore, it has a great role in providing the individual with many language skills and developing children's interest in the language the family speaks.

The main problem begins when the family decides to move to a foreign country that requires leaving what is familiar and moving to a new culture with a new language (Rovira, 2008). This is the reason that lies behind the emergence of the term "language affiliation", meaning the original language spoken by the family in which the children grew up, or that language spoken by the native community of that family $(\mathrm{Ng}, 2017)$.

Thus, the term linguistic inheritance and linguistic affiliation have become synonymous with the single term "native/mother tongue MT" of immigrant families (Figueiredo, 2017, p. 61). Immigrant or expatriate families who live in countries that speak different languages face many challenges, especially at the levels of growing up their children. Indeed, this is the result of the host country's dominant language over the MT of immigrant families (Rovira, 2008).

Hence, there have been many calls that have emphasized the necessity to support native/mother language for immigrant groups to maintain it from foreign language domination (Mattheoudakis, Chatzidaki, Maligkoudi \& Aghathopoulou, 2016). The researcher believes that such support for the MT and maintenance of language affiliation is primarily the responsibility of the family that should contribute to a prominent role in promoting the identity and language affiliation of children.

The importance of the current study is highlighted by the vital role of the family in society as it is responsible for the social, cognitive, emotional and language upbringing of children. It derives significance from the importance of achieving language affiliation as it is one of the most important mechanisms through which Arabic language can be maintained and thereby enhancing Arab children's identity, especially in foreign countries. This study is considered as an addition to the literature, especially in light of the lack of studies that targeted Arab immigrants. The current study aimed at addressing this issue, contributing to helping educational decision-makers in identifying the vital role that the family can contribute in establishing the children's language affiliation. Cooperation between academic institutions and home environments is thus strengthened in this area. At the same time, it will help those who are in charge of designing training programs and linguistic intervention programs in identifying the role that families can contribute to the achievement of language affiliation. Reliance on the principle of comparing the family's role in Arab society with that of the Arab family in foreign communities would help provide accurate indications of the effects of spatial, cultural, and linguistic differences on the children's language affiliation.

Based on the research gap in the current study, as well as the absence of studies that aimed at comparing the role of the family in the Arab community and the role of the Arab family in foreign societies concerning achieving language affiliation, the current problem of the study can be crystallized in determining the role of the family in Saudi Arabia, Austria, and Britain in achieving language affiliation of their children. 
The central research question of the current study is: What is the role of the family in achieving the language affiliation of its children? From this main research question arise several sub-questions that can be reviewed as follows:

- What is the Arab families' role in Saudi Arabia, Austria, and Britain in achieving their children' language affiliation?

- What are the challenges facing families in the Kingdom of Saudi Arabia, Austria, and Britain in achieving the language affiliation of their children?

\section{Literature Review}

Family as a Concept

The family is a term that includes a wide range of definitions and concepts, the most prominent of these concepts are the following: Saleh (2014) defined the family as "a social group of individuals who are bound together by the bond of marriage, blood, or adoption, and they often share common customs and interact together according to the social roles defined by society" (p. 199). Dabla (2015) also defined the family as "a social system consisting of at least one spouse with or without children, as it may extend to other individuals, whose members share specific relationships and include different functions for each role within this system" (p. 30). From the preceding, it can be concluded that the family is considered a social environment built on structured foundations that involve the presence of elements such as parents, children and peers; each of them shares a range of rights and obligations.

\section{Arab families in Saudi Arabia, Austria, and the United Kingdom}

Unlike most other countries, the family in KSA is characterized by close family bonding and parenting of their children to maintain that bonding. This is attained in a coherent system of good customs, traditions, values and virtues. This is what Caldwell (2013) pointed out that the Saudi family system is based on family bonding, and adherence to traditions and customs, and urging to pay attention to the religious aspect. The Saudi family is based on moral values and virtues that include honor, respect for others, generosity, honesty, humility, and dedication. Therefore, the loyalty of the individual to his/her family in the KSA exceeds his/her loyalty to any other societal commitment. The Saudi family is working hard to ensure that children abide by social norms, as well as on raising children to sacrifice all precious things for the sake of family unity and harmony.

Ibn Nafi (2018) has emphasized that the history of the Arabs in the United Kingdom, in particular England, dates back to 1945, when the Arab-Israeli conflict broke for the first time. England was one of the countries that most refugee Palestinian families immigrated to after establishing the State of Israel was released. Afterwards, the decades from the 1960s to the 1990s have seen many immigrants from Arab families of countries such as Yemen, Morocco, Sudan, Syria, and Iraq. It is said that Arab families in the UK are very interested in sending their children to learn in Arab schools and educational institutions on weekends to ensure that their children can speak and write well in Arabic and also to guarantee that they have the opportunity to engage in an educational and social Arab environment. This is an attempt by Arab families in the UK to help their children to maintain their culture, religious beliefs and identity, which are primarily associated with Arabic, the language of Islam and the Holy Quran. 
There are many Arab families in Austria, a large part of which represents all immigrant families due to the conflict in their country of origin, which makes them face housing and living difficulties in Austria. In this regard, Alhashimy (2017) argued that in recent years several thousand people who fled from the scourge of war and who speak Arabic mainly came to Austria. The majority of these people live specifically in Vienna. Still, many of them live in inadequate housing conditions or in very high-priced housing due to the lack of necessary information on the real estate market and the rental laws in the State of Austria.

\section{The Family Role in Achieving Language Affiliation}

The language affiliation of an individual is achieved within the family first. The family is the primary factor in helping the child to interact with others and preserve his mother tongue at the same time. Hancock (2014) pointed out that the family has a significant role in promoting the children's sense of belonging to their native language. This is reflected in what the members of families belonging to minority groups within different societies do. Those families strive to deepen the language affiliation of their children from an early age through focusing their attention on the essential identity of the child and teaching them all issues related to this identity feature, such as language. For example, an individual may live in a community that speaks a specific language and to ensure their language affiliation is not affected, they grew up their children at home to maintain their mother tongue and interact with the outer community in their language. Therefore, the result is that the child grows up and can speak more than one language, ensuring that their MT is still maintained MT, and language affiliation is thus attained.

Many studies have focused on family roles in increasing children's interest in the language. Zetun's (2012) Study indicated that parents' efforts to strengthen and correct their Arabic language would improve language competency. One reason is that children learn from their parents and deliberately imitate their behaviors and attitudes. Parents must therefore pronounce words orrectly, avoid using loan words that have no origin in the language and use classical Arabic as much as possible. While Mosty, Lefever and Ragnarsdóttir's (2013) study indicated that native language communication helps in learning the language and helps parents on informed-decision on what and how to use the native language.

Thus, the official website of the United States Department of Education (2019) indicates the importance of playing the family role in achieving language affiliation, which depends on the family members doing all of the following:

1. To use the MT at home all the time by conversing with children in the family's native language.

2. To tell stories and tales and to perform simple songs in the MT that contains expressions corresponded to the folklore of that language.

3. To address the heritage and culture associated with the language and relate them to books and literature concerned in this field.

4. To attend events involving different families speaking the same language to ensure the child interacts with other people outside the family who can share the same culture and language heritage.

5. To speak with children in the MT, even if they reach the childhood stage. 
From the above, it can be concluded that language affiliation is one of the tasks that the family is required to undertake. This stems from the importance of the individual's adherence to his/her MT despite being in different environments that speak other languages. For this reason, to instill language affiliation in their children, the family should take several steps: (1) to communicate with children in the MT during childhood and even after reaching puberty, (2) to address the heritage and culture of the language origin, (3) to tell stories and songs in MT by parents, and to attend cultural events where people speak the native language and share the same cultural characteristics.

\section{The Importance of Language Affiliation}

The importance of language affiliation lies in strengthening child's racial and cultural roots, thereby preserving their original mentality of drifting towards what might make their native culture disappears. As Steinicke, Walder, Loffler, and Beismann (2001) argued that language affiliation significantly contributes to the process of improving how an individual builds the foundations of social coexistence with the environment to which s/he belongs. This could be attained by what language affiliation provides the individual with ways of assessing social identity and thus enhancing the structure of racial and artistic heritage in general.

From the above, it can be concluded that language affiliation is a critical area, and that importance is represented in both enhancing the ability to own more than one language in addition to the original one, and establishing an individual's identity culturally, and raising motivation rates to maintain the language.

\section{Obstacles to Achieving Linguistic Affiliation}

The individual's language affiliation begins to diminish or be lost when s/he moves to a social and cultural environment that is different from what $s /$ he is used. Thus, it can be said that the challenges to achieving language affiliation are divided into racial, political, and economic obstacles. Other challenges include family, social and educational problems, and challenges that caused by various conflicts and occupation patterns. There are many obstacles that may prevent the family from playing its role in achieving language affiliation for their children. Zaitoun (2012) indicated that there are two challenges facing the family's efforts to enrich the children's language; internal and external changes. Internal challenges that occur within the family such as the weakness of the parents' Arabic language, parents enrollment of their children in foreign schools and universities, the existence of a foreign maid at home and her language on the children. External challenges that occur outside the family include poor Arabic performance in schools, the use of the slang language in environments surrounding children, the use of a hybrid language in modern means of communication (which is a mixture of slang, classical and foreign Arabic language) and the spread of slang-dialect media.

\section{Previous Studies}

Taha (2010) examined the impact of the relationship between the family and the school in developing children's Arabic skills and the effect of the relationship between having an appropriate school environment and providing libraries in developing children's language skills. The study population was composed of the primary schools, families of some of these schools, and families of preschool students in the Locality of Jabal Awliya in Khartoum. The sample study included 50 individuals. The researcher adopted the descriptive-analytical approach and 
used the questionnaire as a tool for the study. Results showed that family and school have significantly developed the children's Arabic skills since family provided a child with a stable family atmosphere that meets all their needs. Other reasons were (1) adopting the optimal way in growing up the child and assisting them with homework, (2) the existence of an appropriate study environment, and (3) the availability of qualified teachers and libraries that contribute to developing children's Arabic language skills. Similarly, Zaitoun (2012) explored the effect of strengthening parents' Arabic and correcting errors for their children. The study also examined the challenges that hindered family's efforts in enriching their children's language, adopting the documentary approach. The major findings obtained from this study were the significant effect of parents ' assistance for developing Arabic for their children by correcting errors they committed. It was observed that the children learned from them and deliberately imitated their behaviors and attitudes. It is recommended that parents must pronounce the words correctly, and avoid using loan words that have no root in the language, do not use foreign terms in Arabic speech, and use the modern standard Arabic as much as possible. Parents should also familiarize themselves with reading and writing to persuade their children about it and encourage them to read and write. The challenges facing the family's efforts to enrich the children's language were: internal and external changes.

To study the impact of diglossia on family and community, Jubara (2013) looked into the most critical linguistic problems facing society and family in the Arab world and identified the linguistic component that affects students. The researcher used the documentary approach as a methodology for the study. Findings revealed that the most critical linguistic problems facing society and the family in the Arab world were Arabic diglossic features, which means the use of two linguistic varieties by individuals in a single linguistic environment or the rival between a written literary language and a common slang language in linguistic use. Concerning the levels of linguistic components that affect the student was the phonemic level. The language was affected by speakers' tongues in some of the letters sounds because both the family and the community pronounce letters in a particular way and the child listens to them and pronounces them incorrectly. Another linguistic component was the morphological level such as grammatical rules and the syntactic level.

Tatar (2015) investigated the linguistic strategies and identities used by parents in Turkish-American immigrant families about maintaining the native language and cultural identity of their children. Tatar (2015) also examined the attitudes of parents and their children about the Turkish language as the original language. The study population consisted of members of one Turkish-American immigrant family resided in Pennsylvania, and the study sample included five members of a Turkish-American immigrant family aged four to 45 years. The study used a qualitative case study approach that used personal interviews to collect data for the study. Results found that there was a high degree of appreciation, appraisal, and positive attitudes among parents and children of Turkish-American immigrant families towards the Turkish language as the native language. There seemed to be a vital role of visiting the homeland in developing the children's native language. Parents played a significant role in the development and maintenance of their children's native language and cultural identity by holding talks in Turkish, not English, continuously visiting Turkey, and teaching children to speak Turkish at home while they were in Turkey to enhance their proficiency in Turkish speaking. Challenges related to facilitating learning of native language and maintaining cultural identity include a lack 
of school support, a lack of communication within the immigrant community, and a lack of time for parents to communicate with children and speak with them in Turkish to maintain the native language and Turkish cultural identity within American society.

Al-Jumaily (2015) explored factors that might lead to the loss of Arabic as a native language of Arab immigrants, and to reveal who is responsible for maintaining the children's original language from parents, schools and governments. The researcher relied on the documentary approach based on the review of previous literature on the loss of the native Arabic language of Arab immigrants and who are responsible for maintaining the original language of children. Results showed that the children's growing up in a foreign environment helps them speak a language other than their native language but gradually makes them lose their native language. The lack of opportunities for children to learn the native language will lead to loss of culture, linguistics, and self-identity. The child's development at home and school environment based on appreciation and bilingual strengthening help maintain the native language and enhance cultural identity.

Cunningham and King (2018) aimed to identify some characteristics related to language, ethnic origins, and affiliation for children from families where one or both parents are foreign speakers in a non-English language, while the children are native speakers of the Malaysian language. The study population was composed of children and their parents from New Zealand families residing in Christchurch, and the sample study included (23) teenagers, (28) parents. The study used the qualitative approach based on personal interviews that were conducted with the study participants. Findings showed that about $83.9 \%$ of the population of Christchurch belongs to Europe, and $7.9 \%$ of the population belongs to Asian origins. Factors related to the self-perceived proficiency of teenagers in the minority language and their perceptions of their race whether of Asian or European roots and the original culture associated with how teenagers choose to use the minority language.

Clycq et al., (2021) investigated how 5-6 $6^{\text {th }}$ year children of Moroccan origin and Belgium natives view language identity and how teachers could have played a pivotal role in enhancing language identity. The authors constructed a survey and administered it to the children's parents. Results showed that Moroccan students belonged more to European language identity than children with Flemish identity. However, Belgium's native children identify more strongly with Flemish than with European identity. This indicates that immigrant children were alienated from their identity due to acculturation and long division and the absence of their mother tongue Arabic.

It seems that there is no single study that investigated the role of family in achieving language affiliation of children in the context of Arab families in Saudi Arabia, Austria, and Britain. Therefore, the current study attempts to tackle this issue by surveying some Arab families living inside Arab countries (i.e. Saudi Arabia) and living overseas (Austria and UK). The justification of choosing such countries lies in that families in Saudi Arabia face almost similar challenges in maintaining Arabic as those families who live abroad due to the outspread of international schools where foreign instructors are involved in teaching kids. Besides, these families adopt foreign nannies to grow up their kids where they have zero background of Arabic. 


\section{Methods}

\section{Research Design}

The author used the descriptive-analytical approach, which Saati (2014) defines as "a form of structured scientific analysis and interpretation, to describe a specific phenomenon or problem and portray it quantitatively and qualitatively by collecting, analyzing data and subject it to study" (p. 93).

\section{Participants}

The sample of the study included 120 parents of those families living in Saudi Arabia, as well as Arab families living in Austria and Britain who were randomly selected. A survey has been administered to 120 families living in Saudi Arabia, Austria, and UK. One hundred nine $(90.83 \%)$ respondents were obtained.

The participants of the current study were composed of 120 Arab parents who were living in Saudi Arabia, Britain, and Austria. The author chose Saudi Arabia because she felt that Arabic is experiencing a challenge to be lost and children do not think language identity due to the effect of studying in international schools where the medium of communication is English. Further, families adopt foreign nannies to bring up their kids at home, and this would affect their mother tongue Arabic. UK and Austria were selected because both countries have a large Saudi and Arab community. More than 180 questionnaires were circulated for many families, but 120 families responded to it. Table 1 summarizes frequency and percentage of those who responded to the questionnaire.

Table 1. Distribution of participants by country

\begin{tabular}{|l|l|l|}
\hline By country & Frequency & $\%$ \\
\hline Saudi Arabia & 52 & $\begin{array}{l}47.7 \\
\%\end{array}$ \\
\hline Austria & 29 & $26.6 \%$ \\
\hline Britain & 28 & $25.7 \%$ \\
\hline Total & 109 & $100.0 \%$ \\
\hline
\end{tabular}

It is evident from Table one that the number of distributed questionnaires was (120), while the received responses were (109) with $(90.83 \%)$, which is quite good. Table one indicates how respondents were distributed as per country, Table two depicts the educational level of the participants, Table three distribution by family member, and Table four distribution by country, economic and social status

Table 2. Distribution of participants by educational level

\begin{tabular}{|l|l|l|l|l|l|}
\hline \multirow{2}{*}{$\begin{array}{l}\text { Educational } \\
\text { level }\end{array}$} & \multirow{2}{*}{$\begin{array}{l}\text { iteration/ } \\
\text { Percentage }\end{array}$} & \multicolumn{2}{|l|}{ Country } & \multirow{2}{*}{ Total } \\
\cline { 2 - 6 } & Saudi Arabia & Austria & Britain & \\
\hline \multirow{2}{*}{ Bachelor or less } & Iteration & 36 & 16 & 9 & 61 \\
\cline { 2 - 6 } & $\%$ & $69.2 \%$ & $55.2 \%$ & $32.1 \%$ & $56.0 \%$ \\
\hline \multirow{2}{*}{ Postgraduate } & Iteration & 13 & 13 & 19 & 48 \\
\cline { 2 - 6 } & $\%$ & $30.8 \%$ & $44.8 \%$ & $67.9 \%$ & $44.0 \%$ \\
\hline
\end{tabular}

ISSN: 2229-9327 
Arab World English Journal (AWEJ) Volume 12. Number 3. September 2021

Family's Role in Achieving Language Affiliation among Children

Al Saud

\begin{tabular}{|l|l|l|l|l|l|}
\hline \multirow{3}{*}{ Total } & Iteration & 52 & 29 & 28 & 109 \\
\cline { 2 - 6 } & $\%$ & $47.7 \%$ & $26.6 \%$ & $25.7 \%$ & $100.0 \%$ \\
\hline
\end{tabular}

Table two shows that the largest percentage of participants distribution by educational level is (\%56) representing (Bachelor or less), followed by (\%44) representing (postgraduate).

Table 3. Distribution of participants by family member number

\begin{tabular}{|c|c|c|c|c|c|}
\hline \multirow[b]{2}{*}{ Family member number } & \multirow{2}{*}{$\begin{array}{r}\text { iteration/ } \\
\text { Percentage }\end{array}$} & \multicolumn{3}{|c|}{ Country } & \multirow[b]{2}{*}{ Total } \\
\hline & & $\begin{array}{l}\text { Saudi } \\
\text { Arabia }\end{array}$ & Austria & Britain & \\
\hline \multirow{2}{*}{ Less than 4} & Iteration & 7 & 19 & 20 & 46 \\
\hline & $\%$ & $13.5 \%$ & $65.5 \%$ & $71.4 \%$ & $42.2 \%$ \\
\hline \multirow{2}{*}{ From 4 to less than 8} & Iteration & 42 & 10 & 8 & 60 \\
\hline & $\%$ & $80.8 \%$ & $34.5 \%$ & $28.6 \%$ & $55.0 \%$ \\
\hline \multirow{2}{*}{ More than 8} & Iteration & 3 & 0 & 0 & 3 \\
\hline & $\%$ & $5.8 \%$ & $0.0 \%$ & $0.0 \%$ & $2.8 \%$ \\
\hline \multirow{2}{*}{ Total } & Iteration & 52 & 29 & 28 & 109 \\
\hline & & $47.7 \%$ & $26.6 \%$ & $25.7 \%$ & $100.0 \%$ \\
\hline
\end{tabular}

It is observed from Table three that the largest percentage of participants distribution by family member number is (\%55) representing (four to less than eight), followed by the percentage (\%42.2) representing (less than four), and in the last order (2.8\%), which represents (more than eight).

\section{Research Instruments}

The researcher designed a descriptive closed questionnaire to explore the family role in achieving language affiliation for children, administered on some families in the Kingdom, Austria and Britain. The questionnaire comprised 38 statements covering two main sections: (1) the role of the family in enhancing language affiliation and (2) challenges face families in achieving language identity. The first section consisted of three sub-sections; cognitive domain, applied domain, and value field. The questionnaire had been constructed in both English and Arabic and sent out to the parents electronically (see appendix A). They had been informed that they had the right to withdraw any time and their identities would remain anonymous.

\section{Research Procedure}

After designing the questionnaire, it has been given to experts for the sake of checking reliability and validity. The panel of reviewers had given their comments on the questionnaire items and provided valuable comments on some statements which need further clarification, and some items either to be merged or removed. The author addressed the reviewers' comments and rebuilt the questionnaire as per the reviewers' comments. After that, it was designed via Google form and the link was distributed to the parents in Saudi Arabia through an international school in Riyadh where the link was sent out to the students' parents' emails. Concerning Arab families in Britain and Austria, it was sent out by Saudi cultural attaches in these countries. 


\section{Statistical Methods}

The data was analyzed using the Statistical Package for the Social Sciences (SPSS) and the results were extracted according to the following statistical methods: (1) frequency and percentages were used to identify the characteristics of the participants according to their demographic data, (2) means and standard deviations to calculate the means of the questionnaire statement as well as the overall scores of the sections and dimensions of the questionnaire based on the participants' responses.

\section{Results}

Q1. What is the role played by families in the Kingdom of Saudi Arabia, Austria, and Britain in achieving their children's language affiliation?

To answer this question, the means and standard deviations of the dimensions of the first section were calculated as follows:

Table 4. Means and standard deviations of the responses of the participants on the dimensions of the first section

\begin{tabular}{|c|c|c|c|c|c|}
\hline \multicolumn{2}{|c|}{ Deviations } & Sample & M & SD & $\begin{array}{l}\text { Response } \\
\text { degree }\end{array}$ \\
\hline \multirow{3}{*}{1} & \multirow{3}{*}{ First dimension: The cognitive domain } & $\begin{array}{l}\text { Saudi } \\
\text { Arabia }\end{array}$ & 3.84 & .765 & high \\
\hline & & Austria & 3.58 & .553 & high \\
\hline & & Britain & 3.62 & .439 & high \\
\hline \multirow{3}{*}{2} & \multirow{3}{*}{ Second dimension: The applied domain } & $\begin{array}{l}\text { Saudi } \\
\text { Arabia }\end{array}$ & 3.24 & .773 & middle \\
\hline & & Austria & 2.94 & 689 & middle \\
\hline & & Britain & 2.96 & .632 & middle \\
\hline \multirow{3}{*}{3} & \multirow{3}{*}{ Third dimension: The value domain } & $\begin{array}{l}\text { Saudi } \\
\text { Arabia }\end{array}$ & 4.01 & .834 & high \\
\hline & & Austria & 3.79 & .555 & high \\
\hline & & Britain & 3.81 & .633 & high \\
\hline \multirow{3}{*}{\multicolumn{2}{|c|}{ Overall average }} & $\begin{array}{l}\text { Saudi } \\
\text { Arabia }\end{array}$ & 3.69 & .718 & high \\
\hline & & Austria & 3.42 & .554 & high \\
\hline & & Britain & 3.45 & .513 & high \\
\hline
\end{tabular}

It is observed from Table four that the general means of the first section dimensions in Saudi Arabia obtained high degree, $(M=3.69, S D=.71)$, indicating the homogeneity of the views of the participants in those dimensions. Furthermore, Table four shows that that means of the first section has got (high) scores, $(M=3.42, S D=.554)$, indicating positive perceptions of the participants towards these dimensions. Concerning families in UK, results also showed that the cognitive dimensions has also obtained high $(\mathrm{M}=3.45, \mathrm{SD}=.513)$, indicating the positive views of the participants toward these dimensions.

Q2. What are the challenges facing families in the Kingdom of Saudi Arabia, Austria, and Britain in achieving their children's language affiliation?

To answer this question, the means and standard deviations of the second section (challenges) were calculated as follows: 
Arab World English Journal (AWEJ) Volume 12. Number 3. September 2021

Family's Role in Achieving Language Affiliation among Children

Al Saud

\section{The Kingdom of Saudi Arabia}

Table 5. Means and standard deviations of the respondents towards challenges that hindered family's role in achieving the language affiliation of children

\begin{tabular}{|l|l|l|l|l|l|}
\hline Section & Sample & M & SD & Order & $\begin{array}{l}\text { response } \\
\text { degree }\end{array}$ \\
\hline \multirow{2}{*}{$\begin{array}{l}\text { The second section: the challenges } \\
\text { facing activating the family's role in }\end{array}$} & $\begin{array}{l}\text { Saudi } \\
\text { achieving the language affiliation of its } \\
\text { children }\end{array}$ & 3.77 & -746 & 3 & high \\
\cline { 2 - 7 } & Austria & 4.16 & -602 & 2 & high \\
\cline { 2 - 7 } & Britain & 4.20 & -429 & 1 & $\begin{array}{l}\text { extremely } \\
\text { high }\end{array}$ \\
\hline
\end{tabular}

Table five reveals that the challenges facing activating the family's role in achieving the language affiliation of their children in KSA has achieved (high) response, $(M=3.77, S D=$. 746). Likewise, the challenges to families in Austria obtained high degree, $(\mathrm{M}=4.16, \mathrm{SD}=.602$.

\section{Discussion}

The current study tested the language affiliation among Arab children living in Saudi Arabia, England, and Austria. It also identified the challenges related to these families in term of mother tongue identity. Results revealed that the cognitive domain obtained higher means score than other domains. This can be attributed to the fact that the family is aware of the importance of the role it has in increasing their children's achievement in their native language. This is evident through adopting many strategies that contribute to supporting their children's affiliation to Arabic language such as speaking the language at home and encouraging children to learn songs and poems in Arabic. This can be attributed to the family awareness of the importance of adhering to the MT alongside other foreign languages, since foreign languages contribute to providing the individual with knowledge and open up prospects for him/her to study a new science. While this does not devalue the MT and its importance, it represents the national identity of the children, the language of the Qur'an and worships, and then the families tend to take many steps and strategies to support Arabic, such as speaking it at home and encouraging children to follow Arabic programs and Arabic literature to enhance their identity and affiliation.

That result is partly consistent with the findings of Tatar's (2015) study that parents play an important and vital role in developing and maintaining the native language and cultural identity of their children through conducting talks in Turkish, not English, making visits to Turkey continuously, and teaching children to speak in Turkish at home to enhance their language proficiency. Likewise, the study is consistent with Taha's (2010) and Zaiton (2012) studies that family has played the pivotal role is shaping the child's language identity and building feeling of belongness to mother tongue.

These positive results of respondents living in UK can be attributed to the fact that the family does not only view language as a means of communication, but rather views it as a way of clarifying and attaining Arab affiliation, love of the land, and being influenced by a concept of loyalty and belonging to the land. The family is considered a positive model for children to adhere to Arabic and encourages them to memorize the Qur'an as the source of Islamic legislation and worships. This would contribute to the development of the language skills of their children, as indicated by parents' awareness of the positive roles they must play to support their 
children's language affiliation. This is also consistent with findings from Tatar (2015), Jubara (2013), and Clycq et al., (2021) indicating that parents play an important and vital role developing and maintaining their children's native language and cultural identity.

Concerning the challenges faced these families as addressed by the second research question, Arab families living in Saudi Arabia are so worried about the issue of language identity for their children despite being in Arab country. This can be attributed to the fact that the Arab world in general and Saudi Arabia in particular, for being the stronghold of Islam, face many threats of their native language, and then the children may be affected by some of the extraneous terms to Arabic, which parents may be unable to perceive and confront.

This is partially consistent with the findings of Jabara (2013) that the most important linguistic problems facing society and the family in the Arab world are the diglossic features of Arabic, which means that individuals are using two linguistic forms in one linguistic environment or a struggle between a written literary form and a common slang language in communication use.

This can be attributed to the insufficiency of some families' Arabic language skills and competencies, in addition to the great influence of the cultural and educational milieu surrounding the children, especially abroad. This result is partly in line with the findings of Zeitoun (2012) that the challenges facing the family in enriching the language of their children are the weakness of the parents' Arabic language, parents' enrolling their children in foreign schools and universities, and the presence of a foreign maid at home, thus affecting the child's native language. That result partly aligned with the findings of the Tatar (2015) that challenges related to facilitating learning of native language and maintaining cultural identity include lack of school support, lack of communication within the immigrant community, and limited time for parents to communicate and speak with children in Turkish to maintain the native language and Turkish cultural identity within American society.

Lastly, the challenges facing families in UK have got a (very high) degree of response $(\mathrm{M}=4.20$, SD.299). This can be attributed to the British people's pride in their culture and heritage and their attempt to impose their cultural identity on the residents of British lands, especially the linguistic side, which makes the Arab families, face many problems in maintaining their children's language affiliation.

\section{Conclusion}

This study investigated the current situation of some Arab families for enhancing language affiliation for their children and the challenges that face families with Arab environment (Saudi Arabia) and foreign environment (UK and Austria). Arab families are suffering from the loss of the native language of their children due to living in an unfamiliar environment and a lack of sources for speaking the native language. Not only that, Arab families living in Arab countries also suffer from the loss of their Arabic language as many families send their children to international schools where there are few opportunities for children to speak and write in their MT. Besides, many families adopt foreign nannies to bring up their children, resulting in acquiring the maid's foreign language and accents. These factors may lead to language loss and the absence of the pride of language affiliation. Results of this study showed 
that Arab families who are living in their homeland and speak their native language also face challenges in achieving language affiliation and language maintenance. Another challenge that meets Arab families who are living abroad is the struggle to maintain Arabic among their children due to diglossic features of Arabic; the an enormous distance between the spoken form (colloquial Arabic) used for oral communication and the literary written form (Classic Arabic) used in books and newspapers.

\section{Recommendations}

In light of the study findings, many recommendations have been raised. First, training programs should be provided for parents to enable them to develop their children's MT and to care for their MT. Second, to establish a mechanism to take advantage of practices available online regarding developing the roles of parents in enhancing the language affiliation of their children. Third, to involve all family members in different extracurricular activities in schools where they can practice their mother tongue as to ease speaking and interacting with peers in their native language. Fourth, parents should encourage children to memorize the Holy Quran. Fifth, the role of social media in developing the language affiliation of children should be enhanced. Sixth, the role of the various cultural centers and attachés of Arab embassies should be activated in developing the children's language affiliation.

\section{Study Limitations and Suggestions for Future Research}

The current study has many limitations. First, the study was limited to Arab families living in one Arab country and two foreign countries. More future studies were recommended to cover families living in many countries and identify the current situation and the challenges they struggle to maintain their native language for their children. The present study had collected data via a questionnaire which is known as limited in obtaining accurate results. Future studies need to conduct ethnographical studies to give a fine-grained picture about how Arabic is maintained and what the optimal ways Arab families do for maintaining their language and attaining language affiliation for their children. More studies are recommended to explore the role of the family in maintaining the cultural identity of children who are living abroad.

\section{About the author:}

Dr. Aljohara Fahad Al Saud is an assistant professor of Early Childhood, Department of Early Childhood, College of Education, King Saud University. She has published several papers in national and international journals. She is a member of many international Educational associations. Her research interest includes early childhood, language identity, language affiliation. Her orcid account is https://orcid.org/ 0000-0002-8806-0694

\section{References}

Alhashimy, S. (2017). Wohnen In Österreich-Eine Informationsbroschüre Auf Deutsch Und Arabisch. Vienna: Samariterbund.

Al-Jumaily, S. (2015). Parents' first language is their children's second language. Language loss: Arabic is a case. International Journal of English Language Teaching, 2(2), 19-31.

Altaie, H. A. (2009). Nashat Allagha [Language Generation]. Educational Studies, 6, 195-220.

Ben Nafa, H. (2018). Code-Switching as an evaluative strategy: Identity construction among ArabicEnglish bilinguals in Manchester, (Unpublished Ph.D. Dissertation). Manchester Metropolitan University, UK. 
Bou Raad, E. P., Hallit, S., Iskandar, K., \& Zeenny, R. M. (2017). Validation of a patientpharmacist relationship measurement tool in Lebanon. RRJPPS, 6(2), 1-10.

Caine, T. M. (2008). Do you speak global?: the spread of English and the implications for English language teaching. Canadian Journal for New Scholars in Education, 1(1), 1-11.

Caldwell, J. D. (2013). Examining the experiences and adjustment challenges of Saudi Arabian students in the California state university system, (Unpublished Ph.D. Dissertation). California State University, USA.

Chung, K. H. (2014). Nonnative speaker teachers' professional identities: The effects of teaching experience and linguistic and social contexts, (Unpublished Master's Thesis). University of California, Los Angeles.

Cole, M. (2008). The importance of parental involvement in language acquisition and activities and techniques to enhance the home-school connection, (Unpublished Master's Thesis). Washington University School of Medicine, USA.

Clycq, N., Driezen, A., \& Verschraegen, G. (2021). (Sub) national and supranational identity among majority and minority youth in superdiverse urban schools. Journal of Youth Studies, 24(5), 563-579. https://doi.org/10.1080/13676261.2020.1747604

Cunningham, U., \& King, J. (2018). Language, ethnicity, and belonging for the children of migrants in New Zealand. SAGE Open, 8(2), 1-11. https://doi.org/10.1177/2158244018782571

Dabla, K. (2015). dawr altasadue al'usrii almaenawii fi zahar alaightirab alnafsii ladaa almarahiq. [The role of the family moral crack in the back of adolescent psychological alienation : A case study of some adolescents] Sudan: Dar Al Jinan for Publishing and Distribution.

Das, G., \& Priya, M. (2017). Family History and Its Influence on Infants' Language Development. Universal Journal of Psychology, 5(1), 8-16. DOI: 10.13189/ujp.2017.050102

Dean-El, V. (2019). Understanding social workers' roles providing case management to Medicaid managed care enrollees, (Unpublished $\mathrm{PhD}$ Dissertation). Walden University, USA.

Figueiredo, S. (2017). Learn a second language first a guide for L2 research in the context of languages other than English. USA: Library of Congress Cataloging-in-Publication Data.

Hamida, A. (2010). Taheel alwaldain wa afrad alosra limutabat taqiim alnomo allagawi liabnaehim fi almarhala alasasia lsafof alarba alola [Rehabilitation of parents and family members to follow up on evaluating the linguistic development of their children in the basic stage of the first four grades]. The 20th cultural season of the Jordanian Arabic Language Academy, Amman, 23 October.

Halawa, B. (2011). Dawr alwalidayn fi takwin alshakhsiat alaijtimaeiat eind al'abna' dirasa maydaniat fi madinat dimashq [The role of parents in the formation of social personality of children, a field study in Damascus] . Damascus University Journal, 27 (3/4), 71-109.

Hancock, A. (2014). Chinese Complementary Schools in Scotland and the Continua of Biliteracy. In X-L, Curdt-Christiansen, \& A. Hancock (Eds.), Learning Chinese in Diasporic Communities: Many Pathways to Being Chinese, (pp. 59-80). Amsterdam: John Benjamins. 
Ibn Nafa, H. (2018). Code-Switching as an Evaluative Strategy: Identity Construction among ArabicEnglish Bilinguals in Manchester, (Unpublished PhD Dissertation). Manchester Metropolitan University, UK.

Jin, L. (2015). Developing Chinese complimenting in a study abroad program. Chinese Journal of Applied Linguistics (Quarterly), 38(3), 277-300.https://doi.org/10.1515/cjal-2015-0018

Jubara, O. B. (2013). Izdewagiat Allaga wa athrha fi almugtama. [Bilingualism and its impact on society and the family]. Journal of Family Studies, 3, 110-134

Mattheoudakis, M., Chatzidaki, A., Maligkoudi, C., \& Agathopoulou, E. (2016). Family and school language input: their role in bilingual children's vocabulary development. JAL 31, 49-69. https://doi.org/10.26262/jal.v0i31.8291

Mead, A. (2013). Identity and sentient emotions at work, (Unpublished PhD Dissertation). Macquarie University, Australia.

Merriam-Webster Dictionary. (2020, June 1). Role. Available at https://www.merriamwebster.com/dictionary/role?utm_campaign=sd\&utm_medium=serp\&utm_source $=$ jsonld

Mosty, N., Lefever, S., \& Ragnarsdóttir, H. (2013). Parents' perspectives toward home language and bilingual development of preschool children [Special Issue 2013-Research and School Practice. University of Iceland, School of Education]. Netla-Online Journal on Pedagogy and Education. Retrieved from http://netla.hi.is/serrit/2013/rannsoknir_og_skolastarf/006.pdf

Muhammad, S. (2012). Aldawr altakamuli lil'usra walrawda fi eamaliat altanshia alaijtimaeia. [The integrative role of the family and kindergarten in the process of social upbringing]. Journal of Humanities, 8, 110-125.

Ng, P. C. L. (2017). A Study of attitudes of dialect speakers towards the speak mandarin campaign in Singapore. $1^{\text {st }}$ Ed., Cham, Springer.

Rovira, L. C. (2003). The Relationship between Language and Identity. The Use of the Home Language as a Human Right of the Immigrant. REMHU - Revista Interdisciplinar da Mobilidade Humana, XVI(31), 63-81.

Saati, F. (2014). al'idara alriyadia manahij albahth al'ilmi fi al'iidara alriyadia [Sports Management Scientific research approaches]. Cairo: Al-Arabi for Publishing and Distribution.

Saleh, A. (2014). alkhidma alaigtimaeia wa majalat almumarasat almihaniea. [Social service and areas of professional practice] . Egypt: Modern University Office.

Steinicke, E., Walder, J., Loffler, R., \& Beismann, M. (2010). Autochthonous Linguistic Minorities in the Italian Alpes: New Legislation - New Identifications - New Demographic Process. Journal of Alpine Research, 99(2), 1-14. DOI : 10.4000/rga. 1454

Taha, B. (2010). dawr al'usra fi tanmiat mahara allugha alearabia ladaa al'atfal: dirasa wasafia tahlilia limarhalat ma qabl almadrasa walhalqa al'uwlaa min marhalat al'asas, mahaliyat jabal 'awlia' [The role of the family in developing Arabic language skills of children: A preschool analytical descriptive study and the first level of the basic stage, Jabal Awliya locality] (Unpublished Master's Thesis), Omdurman Islamic University, Sudan.

Tamis-LeMonda, C. S., \& Rodriguez, E. T. (2009). Parents' Role in Fostering Young Children's 
Learning and Language Development. Language Development and Literacy, Encyclopedia on Early Childhood.

Tatar, R. (2015). Parents' role in their children's development and maintenance of the heritage language: A case study of a Turkish-American immigrant family, (Unpublished Master's Thesis). Indiana University of Pennsylvania, Indiana.

The United State Department of Education. (2019, November 19). Talk, read and sing together every day!: tips for using language at home and the community. Available at https://bit.ly/35bQRdy.

Zaitoun, M. (2012).al'usra wadawruha fi 'ighna' lughat 'abnaiha [The family and its role in enriching the language of its children]. The Arab-Arabic Renaissance Ways Conference the 30th Cultural Season of the Arabic-Jordanian Language Academy, NovemberMuharram, Amman. 